\title{
Research on the Current Situation and Promotion Strategy of Qiang Embroidery Inheritance in Qiang Village of Xiuxi Based on the Perspective of Living Inheritance
}

\author{
Binjie Cheng \\ Town Planning and Management in Ethnic Areas, School of Architecture, Southwest Minzu University, Chengdu, China \\ Email: 843809823@qq.com
}

How to cite this paper: Cheng, B.J. (2020) Research on the Current Situation and Promotion Strategy of Qiang Embroidery Inheritance in Qiang Village of Xiuxi Based on the Perspective of Living Inheritance. Open Access Library Journal, 7: e6926. https://doi.org/10.4236/oalib.1106926

Received: October 24, 2020

Accepted: November 24, 2020

Published: November 27, 2020

Copyright (๑) 2020 by author(s) and Open Access Library Inc.

This work is licensed under the Creative Commons Attribution International License (CC BY 4.0).

http://creativecommons.org/licenses/by/4.0/

\section{Open Access}

\begin{abstract}
Living inheritance not only refers to the inheritance of key skills, but also relates to the prosperity and growth of the entire Qiang culture. Qiang embroidery is the material carrier of the traditional skills of the Qiang people. Xiuxi Qiang Village is a typical pure Qiang Village. Qiang embroidery flourishes here, but it also faces many problems, such as low recognition by villagers and insufficient policy support. This article understands the current situation of Qiang embroidery development and the problems faced by collating the existing literature, and proposes to promote the regional economy, build the material basis for inheritance, realize the reconstruction of inheritance concepts, strengthen publicity and brand building, the construction of cultural service facilities, and the development of talents. In this way, it promotes the double prosperity and development of Qiang embroidery and local culture and economy of Qiang Village in Xiuxi.
\end{abstract}

\section{Subject Areas}

Culture

Keywords

Living Inheritance, Qiang Embroidery, Xiuxi Qiang Village

\section{Research background}

As an important carrier of the wisdom of the Qiang culture, Qiang embroidery is the spread of national culture, the eternal continuity of the nation, and the im- 
print in the depths of the soul. In the process of human history and civilization, Qiang embroidery is the past and existing, and is the eternal treasure of the nation [1]. The inheritance of Qiang embroidery is a unified and harmonious carrier of human, nature, and religion. It is the embodiment of its understanding of the concepts of auspiciousness, survival, and harmony. It is an organic whole that embodies the unified concept of the nation. It reflects the national emotions and thoughts. For the entire social life of the Qiang people, it is part of it. However, with the acceleration of the modernization process, many young people of the Qiang ethnic group lack a certain understanding of their own national culture. Therefore, the traditional cultural treasure of Qiang embroidery is actually faced with a lack of type, a fault in skills and even its disappearance to a certain extent [1]. These are all obstacles facing the sustainable development of Qiang embroidery. According to incomplete statistics, in areas where the Qiang population accounts for more than $90 \%$ of the total population, the number of people engaged in Qiang embroidery is about 27\%, and the average monthly income is about 1500 yuan. However, in some areas with a small population of Qiang people, the development of Qiang embroidery is facing huge problems.

Xiuxi Qiang Village (Figure 1) is one of the "fourth batches of traditional Chinese villages" announced in 2016. It has a history of several thousand years, and the ancient Qiang culture has been passed down from generation to generation in Xiuxi [2]. Confucian Confucianism, Shibi play, embroidery with flowers, wine sacrificial offerings, and Qiang songs and dances are all treasures left by history. The Qiang people in Xiuxi Village can sing, dance, and are warm and hospitable. Their unique Qiang culture has now become the cultural icon of $\mathrm{Li}$ County. Li County has held the Puxi Chuan Confucian Festival in Xiuxi Village for 7 consecutive years to spread and promote ancient Qiang culture. After the 2008 earthquake, villagers in Xiuxi Village, Puxi Township, Li County, Aba Prefecture, Sichuan Province still stayed in the Qiang Village where their ancestors lived for nearly a thousand years, and rebuilt authentic Qiang-style houses on the original site [3]. After the earthquake disaster, the retention of ethnic characteristics in the village and the infiltration of new elements added new vitality and vitality to the village, which are waiting for future generations to explore and discover. As an important carrier of traditional national culture and rural culture, Qiang embroidery can represent the spirit of the village and local regional

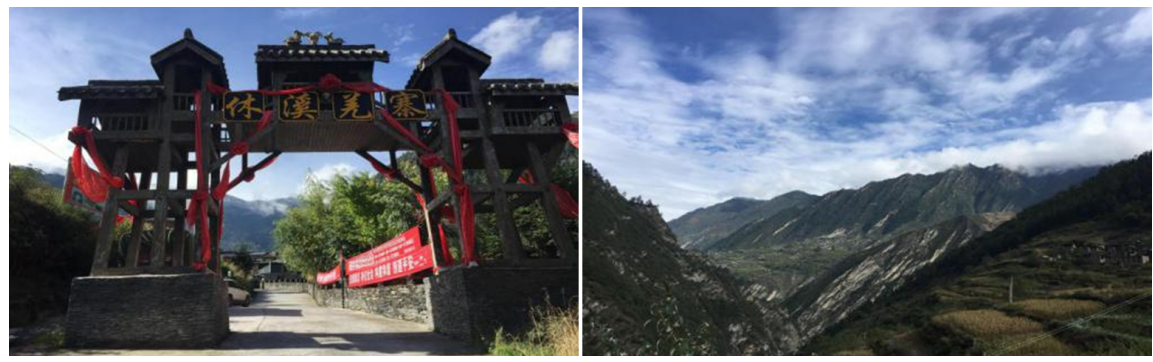

Figure 1. Entrance and surrounding environment of Xiuxi Qiang Village photoed by the author. 
cultural characteristics to a certain extent; at the same time, the inheritance and development of Qiang embroidery can also promote the development of the local economy [4]. Therefore, through Qiang embroidery, the integration of other local functions is to promote the revival of local economy, history and culture, but at the same time, we have to face the huge problems facing the development of Qiang embroidery in Xiuxi Qiang Village.

Historical carriers and profound cultural connotations are important features of Qiang embroidery. Therefore, it is one of the carriers of the spiritual culture of the Qiang people. For my country's intangible cultural heritage, Qiang embroidery is also an extremely important treasure. In recent years, my country has paid more and more attention to intangible cultural heritage, and has promulgated multiple policies and regulations, and the legal system for the protection of intangible cultural heritage has gradually improved. The report of the 19th CPC National Congress also mentioned the protection of intangible cultural heritage. Therefore, it is not difficult to find that the state attaches great importance to it and continues to pay attention to it. In addition, in June 2008, Qiang embroidery was included in the second batch of national intangible cultural heritage lists, and its importance has continued to deepen. It serves as a cultural reality carrier of what Qiang people have learned, used, and wanted in their long lives. It is inherently indivisible. Because it has witnessed the evolution of the historical development of the Qiang people, and is also the spiritual sustenance of the Qiang people in the long years, which is of great research value.

\section{Research Significance}

1) Theoretical significance

After the earthquake disaster, the retention of ethnic characteristics in the village and the infiltration of new elements added new vitality and vitality to the village, which are waiting for future generations to explore and discover. Qiang embroidery, which symbolizes traditional national characteristics, is an important carrier for presenting rural culture, highlighting the local rural spirit and regional culture; secondly, the revival and development of Qiang embroidery is a catalyst for the revival and development of the region. By integrating the various functions of the village, promote the development of local agriculture and tourism, and promote the revival of local economy, history and culture [5].

For Qiang embroidery to develop, it must be inherited, and what has been frequently mentioned in the academic circles in recent years is "live inheritance". The so-called live inheritance not only refers to the inheritance and continuation of key skills, but also concerns the entire Qiang ethnic group. The prosperity and growth of culture is committed to the overall coordinated development of surrounding policies, life, society, and psychological environment. Therefore, taking the traditional pure Qiang village as an example to study will make up for the shortcomings in the protection and development of traditional inheritance, help focus on the development of the overall environment and atmosphere, and faci- 
litate the itinerary of the Qiang culture inheritance system, as well as promote its spread [6]. While letting people understand the culture of Qiang nationality, it can also promote the innovation and development of Qiang embroidery, which is beneficial to the formation of systematic and scientific theoretical knowledge of Qiang embroidery.

2) Practical significance

Ethnic minorities are an indispensable part of the Chinese nation, and ethnic minority cultures have their own characteristics and values [7]. Therefore, it is extremely important to innovate their culture on the basis of inheritance, which is extremely important for the continuation of national culture. In the customs of the Qiang nationality, women of the Qiang nationality will start learning Qiang embroidery from the age of ten. The phrase "one study to cut, two studies, and three studies to embroider cloth shoes" is one of the important inheritances of Qiang embroidery, which can be clearly described. Qiang embroidery is the basic skill that Qiang women need to master before marriage. However, with the development of the times, the Qiang population has moved from settlements to cities [8]. Driven by science and technology, the Qiang embroidery skills passed down from hand to mouth are gradually disappearing. The demand for Qiang costumes has been greatly reduced. Coupled with the diminishing of various traditional customs and habits, the talents for the inheritance of Qiang embroidery are in a state of shrinking overall. Therefore, research on Qiang embroidery is of dual significance. On the one hand, with the spread of mechanization and the improvement of living standards, people pay more attention to cultural life, and the demand for traditional handicrafts increases; the inheritance of embroidery culture can maintain the fresh vitality of the Qiang ethnic culture.

\section{Folk Inheritance of Qiang Embroidery Craftsmanship}

The inheritance of Qiang embroidery is mainly based on folk inheritance, that is, family inheritance is the dominant one. Teaching by precept and example is the main form of Qiang embroidery inheritance.

1) Family and family-led inheritance methods

The family-themed communication method is the most important method for the inheritance of Qiang embroidery [8]. As the basic unit of the inheritance of Qiang embroidery, the family inheritance method has become one of the indispensable inheritance methods. The family is the basic platform for the display of national culture and the basic place for the inheritance and continuation of traditional culture. The inheritance of Qiang embroidery is through the inheritance within the family, so it can be widely inherited and protected and developed among the people, making the national intangible cultural heritage of Qiang embroidery multiply to this day.

2) Inheritance in village activities

Like other Qiang villages, Xiuxi Qiang Village has various ethnic minority traditional festivals. In these activities, all people in the stockade will actively 
participate [6]. The village activities of Qiang culture are also a good platform for Qiang embroidery to show each other, appreciate each other, and learn from each other. At the same time, it is also an opportunity for emotional exchanges among residents of the village [9]. In such a process of exchanges, a strong internal cohesion is formed invisibly. However, through communication with local people, I learned that due to the sharp decline of young people in the village, the number of traditional festivals held within the village has drastically reduced.

3) Mutual learning and reference among peers

How well the Qiang embroidery craftsmanship is inherited is largely related to people's exchanges and interactions with each other, as well as their relationships, especially with relatives and friends. For example, a woman who is skilled in embroidery, and she likes to chat and communicate with people in Qiang villages. This kind of extensive interpersonal communication is conducive to the inheritance of national handicrafts. On the surface, it is only related to manual skills, but what really reflects is the interpersonal relationship.

4) Problems in Qiang Embroidery

\section{Compressed Living Space of Qiang Embroidery}

Nowadays, people's recognition of Qiang costumes is very low, and many people don't even know the existence of Qiang embroidery. Most of the young people of the Qiang nationality actively or passively abandon their traditional costumes because they feel that their national costumes are rustic. Embroidery is an accessory and external form of Qiang clothing, and they complement each other [7]. The possession and frequency of Qiang costumes are constantly decreasing. With the development of society, historical changes, and the infiltration of mainstream culture, Qiang costumes have gradually lost their former glory. Many young people from ethnic minorities feel that they are no longer proud and confident of wearing Qiang costumes. Instead, they feel that they are outdated and unable to keep up with the development of the times, thinking that Qiang embroidery is too conservative.

1) The number of inheritors of national culture is small

There are even fewer people who can fully master all kinds of embroidery methods. The lost situation of Qiang embroidery is also reminding people of the disappearance of traditional culture at any time. Through interviews, we learned that the age of people who can fully grasp Qiang embroidery is basically over 60 years old. Only a few people under 60 can fully grasp $\mathrm{Wu}$ embroidery method, and the position of traditional Qiang village is very important for Qiang. Xuixi Qiangzhai is too far away for minority areas.

The traces of national culture are also getting faint. With the gradual passing of the older generations who have the skills of Qiang embroidery, there are few young people who want to learn Qiang embroidery. If the corresponding rescue measures are not timely, the most primitive ecological tradition of pure manual art will disappear. 
2) Impact of tourism interests

In the pursuit of economic interests, many scenic spots and cultural constructions in tourist areas have neglected cultural connotations. People only take photos and post to friends in the process of traveling, but they don't know how to appreciate and recognize the history behind those traditional cultures. The story, even the tour guides who are often stationed in the scenic spot, don't know enough about the content, but only a little understanding.

People's love for Qiang embroidered clothing should be a feeling that does not involve any utilitarian emotions. In order to cater to the curiosity of tourists, it has put a lot of pressure on Qiang costumes. If you deliberately embrace the theme of cultural journey, many ethnic costumes may lose their original style and charm, and the originally simple, harmonious, exquisite craftsmanship, and unique style of costumes will gradually lose their appeal.

\section{Research on the Promotion Strategy of Live Inheritance of Qiang Embroidery}

Living inheritance includes the inheritance and continuation of key skills. While it is related to the prosperity and growth of the entire Qiang culture, it also enables the overall coordinated development of surrounding policies, life, society, and psychological environment. Therefore, the government and society should try their best to promote and maintain all aspects to create a good environment for the inheritance of Qiang embroidery.

1) Promote regional economy and build a material foundation for inheritance

National culture and regional economy are interdependent. Cultural development is inseparable from economic development, and economic growth is also inseparable from cultural prosperity. They are not only interdependent, but also can form a harmonious and unified development.

All in all, an excellent national culture and a healthy and beneficial regional economic environment are the actual material basis for the continuous inheritance of national culture. Cultural development, improved economic efficiency, and harmonious development of culture and economy can enrich and strengthen the material foundation of cultural inheritance and maximize the permanent inheritance of national culture.

2) Having both humanistic spirit and realizing the reconstruction of inheritance concepts

In the process of communication in human society, beauty, happiness and happiness are the most important to the public. Therefore, in order to promote social peace and harmony, it is imperative to place culture and economic development at the same height. If traditional culture is sacrificed only for economic development, the economy will lose its cultural foundation and development will enter a bottleneck period. Nowadays, economy and culture itself are mutually reinforcing whole and are inseparable. Therefore, cultural inheritance with the sole purpose of economic development is only the shell of culture, which is des- 
tined to lose the spark of civilized ideology. Ignore the humanistic spirit contained in the culture itself.

Qiang embroidery fully embodies people's yearning for a better life, nature's love, and persistent pursuit of truth, goodness and beauty. It has been integrated into the long river of Qiang culture and history, and embodies the cultural freedom of the Qiang people who love life and nature. If these unique cultural cores are lost, Qiang embroidery can only become a piece of cloth embroidered with flowers.

3) Improve quality, strengthen publicity and brand building

The Qiang embroidery is also facing the problem of mass production. The general principle is to focus on the quality of products, create a national brand with creativity and characteristics under the premise of ensuring quality, and help local residents and enterprises to establish an appropriate brand image. This will not only achieve economic improvement, but also solve the employment problem of some people. More young people are retained in ethnic areas.

Good brand publicity and a trustworthy corporate brand image will effectively promote the inheritance of Qiang embroidery culture and enable Qiang embroidery to move from the countryside to the society and to the road of prosperity and development.

4) Construction of cultural service facilities and cultivation of talents

Infrastructure is the material basis for the effective inheritance of culture. The local government should implement funding guarantees and strive to improve the infrastructure construction in ethnic areas, such as the construction of basic-level cultural service stations such as libraries and cultural centers. And it's free of charge, not only attracting local people and even when tourists come to visit, but also through museums to popularize cultural dissemination and promotion. You can also learn from other regions to set up special funds for cultural construction, and protect them through laws and regulations, and use coercive force to ensure that the special funds can be used for the inheritance and promotion of cultural undertakings.

In terms of talent training, we can't simply recruit a few staff, but give priority to choosing people who truly love our national culture and have a certain Chinese ability to participate in the development of the nation's tourism and Qiang embroidery, so that they can devote themselves to the development of tourism and Qiang embroidery. Yongxinda works in order to achieve higher efficiency.

\section{Research Methods and Shortcomings}

This article adopts field investigation method and literature research method.

1) Field research method

This article adopts the field research method. During the summer vacation, I drove with my family to Xiuxi Qiang Village to take pictures of the scene and chat with local residents (Figure 2 and Figure 3 ). In this pleasant and easy process, I obtained interview materials about the current situation and problems of Qiang embroidery. 

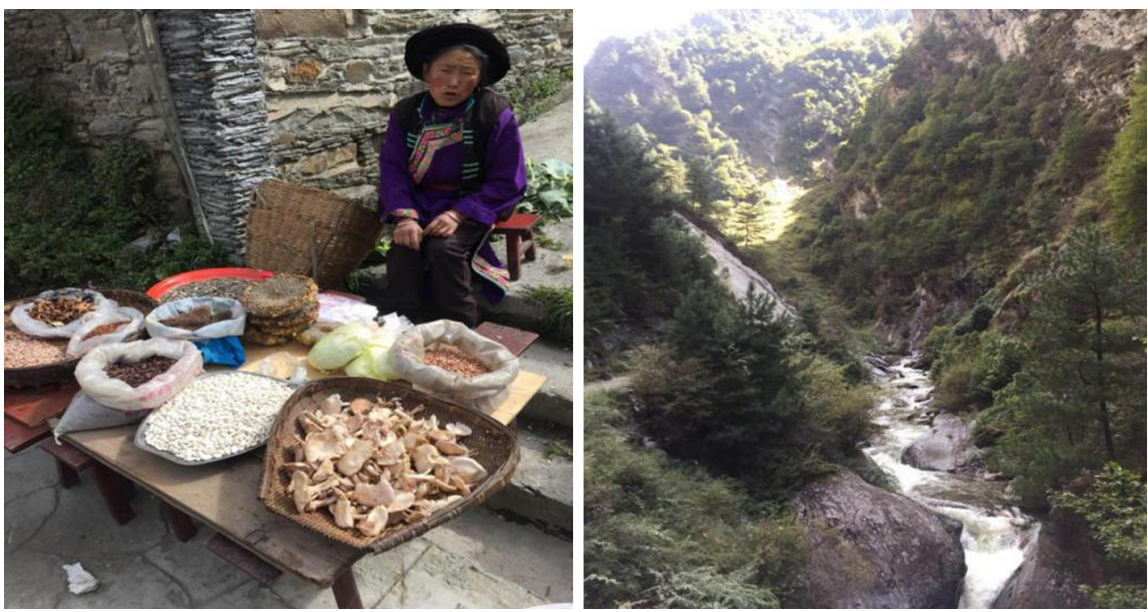

Figure 2. Field investigation photo by the author.
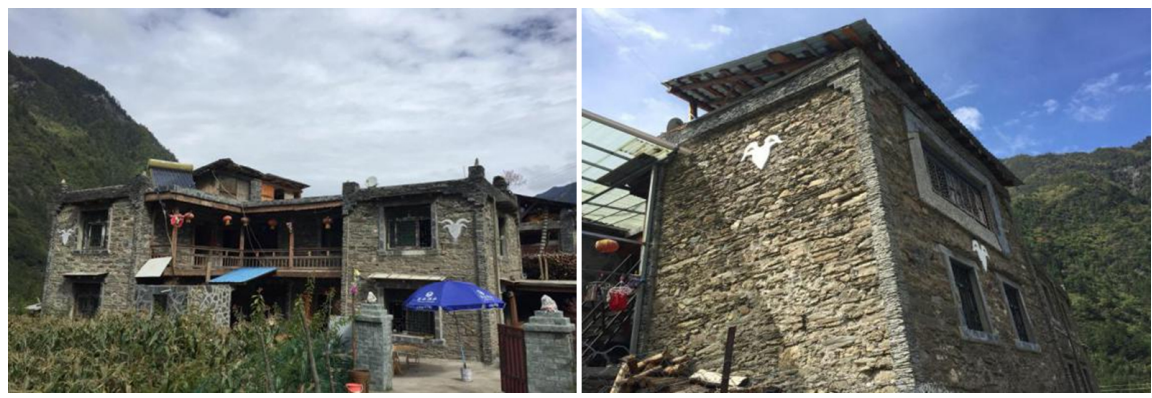

Figure 3. Buildings of Xiuxi Qiang Village photo by the author.

\section{2) Literature analysis method}

This article mainly uses HowNet to search keywords to obtain relevant references, sort and summarize the documents, and obtain the main information about the development and current situation of Qiang embroidery.

3) Deficiencies

The theme selection is in line with the professional goals and characteristics of ethnic regions, and the theme selection is very targeted and realistic. Writing is related to relevant literature and topics. First-hand data is obtained through field research, which can improve the authenticity of the paper's opinions. However, the shortcomings of this article are that the sentence statement is not concise enough, the reference materials are relatively old, the argument is not deep enough, the innovation is not enough, and the references are also few.

\section{Conclusions}

As the essence of Qiang culture, the existence of Qiang embroidery itself is the most special symbol of its ethnic group, which distinguishes it from other ethnic groups. But nowadays, under the impact of economic development and mechanical duplication, the inheritance of the most original traditional culture is facing a fault. The inheritance of Qiang embroidery requires tremendous efforts.

It is worth noting that while advancing the industrialization of Qiang em- 
broidery, we must handle the relationship between communication and protection. We must not blindly pursue the economic benefits brought by industrialization and ignore the core soul elements of the Qiang culture carrier. Of course, we should not blindly protect and neglect its economic spread. Nowadays, economicalization and culturalization are interdependent. The best way to gain economic benefits while maintaining cultural purity is to let the traditional handicrafts of ethnic minorities enter modern life, and even seek the best combination with local tourism. This is an effective way to promote its long-term survival and development.

\section{Acknowledgements}

First of all, I would like to thank my supervisor for taking the time to revise my paper during his busy schedule, and for providing many key and effective opinions for my paper.

I would like to thank my family for their academic support, and thank the roommates for their understanding and support.

\section{Conflicts of Interest}

The author declares no conflicts of interest regarding the publication of this paper.

\section{References}

[1] Pan, Y. (2017) Qiang Nationality Folktale Part One Sichuan. Maowen Qiang Autonomous County Cultural Center.

[2] Ran, G., Li, S. and Zhou, X. (1985) Qiang Clan History. Sichuan Nationalities Publishing House, Chengdu.

[3] Zhong, M., Fan, X. and Fan, P. (2012) Qiang Costume and Qiang Embroidery. China Textile Publishing House, Beijing.

[4] Yan, R. (2017) The Social and Cultural Function and Inheritance of Qiang Embroidery. Journal of Chengdu Textile College.

[5] Huang, D. and Hou, X. (2017) Countermeasure Analysis on Protection and Inheritance of Qiang Embroidery Culture in Sichuan after Earthquake. Masterpiece Appreciation.

[6] Yang, L. (2014) The Inheritance and Development of Qiang Embroidery. Tourism Overview (Second Half of the Month).

[7] Xiong, L. (2017) Analysis of Countermeasures for the Protection and Inheritance of Sichuan Qiang Embroidery Culture after Wang Jianzhen. Sichuan Drama,.

[8] Zhang, T.M. (1995) The Historical Trace of Zhang Taiming's Embroidering of the Qiang People. Guizhou Ethnic Studies.

[9] Zhao, S. (1995) On the Inheritance of National Culture. Journal of Yunnan Nationalities University (Philosophy and Social Sciences Edition). 